\title{
Risk factor analysis of clinical outcomes of total aortic arch replacement and frozen elephant trunk with aortic balloon occlusion
}

Luchen Wang, Yunfeng Li, Yaojun Dun and Xiaogang Sun * (1)

\begin{abstract}
Background: Total aortic arch replacement (TAR) with frozen elephant trunk (FET) requires hypothermic circulatory arrest (HCA) for 20 min, which increases the surgical risk. We invented an aortic balloon occlusion (ABO) technique that requires 5 min of HCA on average to perform TAR with FET and investigated the possible merit of this new method in this study.

Methods: This retrospective study included consecutive patients who underwent TAR and FET (consisting of 130 cases of ABO group and 230 cases of conventional group) in Fuwai Hospital between August 2017 and February 2019. In addition to the postoperative complications, the alterations of blood routine tests, alanine transaminase (ALT) and aspartate transaminase (AST) during in-hospital stay were also recorded.

Results: The 30-day mortality rates were similar between $\mathrm{ABO}$ group (4.6\%) and conventional group (7.8\%, $P=0.241)$. Multivariate analysis showed $A B O$ reduced postoperative acute kidney injury $(23.1 \%$ vs. $35.7 \%, P=0.013)$ and hepatic injury (12.3\% vs. $27.8 \%, P=0.001)$, and maintained similar cost to patients ( 25.5 vs. 24.9 kUSD, $P=0.298$ ). We also found that AST was high during intensive care unit (ICU) stay and recovered to normal before discharge, while ALT was not as high as AST in ICU but showed a rising tendency before discharge. The platelet count showed a rising tendency on postoperative day 3 and may exceed the preoperative value before discharge.
\end{abstract}

Conclusions: The ABO achieved the surgical goal of TAR with FET with an improved recovery process during the inhospital stay.

Keywords: Total aortic arch replacement, Frozen elephant trunk, Hypothermic circulatory arrest, Aortic balloon occlusion, Hepatic transaminase, Blood transfusion

\section{Introduction}

Total aortic arch replacement (TAR) by using the frozen elephant trunk (FET) technique is the standard procedure to treat aortic disease involving repair of the aortic arch and proximal descending thoracic aorta in our hospital [1-3] as well as in many aortic centers in the world

\footnotetext{
*Correspondence: xiaogangsun|@163.com

Aortic and Vascular Surgery Center, Fuwai Hospital, National Center for Cardiovascular Diseases, Chinese Academy of Medical Sciences and Peking Union Medical College, No.167 North Lishi Road, Xicheng District, Beijing 100037, China
}

[4-12]. Most recently, an aortic balloon occlusion (ABO) technique was applied to TAR and FET that consistently shortened the lower body circulatory arrest (CA) time and further raised the target nadir temperature setting point for CA [13]. This ABO technique allowed continuous perfusion to abdominal end organs during TAR and FET and eliminated the need for prolonged lower body $\mathrm{CA}$, because it required only $5 \mathrm{~min}(\mathrm{~min})$ on average to set up the $\mathrm{ABO}$ device before the lower body $\mathrm{CA}$ was ended and the following procedure (the distal aortic anastomosis in TAR and FET) could last as long as needed. The present study investigated the effects of the 
$\mathrm{ABO}$ technique on the postoperative recovery process, clinical outcome, and blood transfusion of the TAR and FET operation, as well as explored the risk factors for these events. By comparing the strength of the protective effect of the $A B O$ technique statistically against the other risk factors, we aimed not only to discover to what extent the $\mathrm{ABO}$ technique has improved the clinical results, but also to explore how the other risk factors could affect different clinical results. The significance of the $\mathrm{ABO}$ technique among all factors could guide the usage of this approach for each patient according to the preoperative conditions.

\section{Methods}

\section{Patient selection}

We reviewed the in-hospital record of all these patients, which were the routine parameters from our institution and did not constitute any additional burden for the patients. The cases of the consecutive patients who underwent the TAR and FET operation in Fuwai Hospital between August 2017 and February 2019 were reviewed, including those of 130 patients who received the new TAR and FET by ABO and 230 those of patients who received the conventional TAR and FET. The perioperative details were separately recorded and compared to investigate the possible merit of the $\mathrm{ABO}$ technique.

\section{Surgical approach}

In the surgical procedure, arterial cannulation was achieved using the right axillary and femoral arteries, delivered with a Y-connector from the single arterial line. After the nasopharyngeal temperature reached $28{ }^{\circ} \mathrm{C}$, the femoral line was clamped and lower body CA was initiated, while unilateral antegrade selective cerebral perfusion was delivered via a right axillary line at the rate of $5-10 \mathrm{~mL} / \mathrm{kg}$ per min with the proximal right innominate artery clamped. The descending aorta was implanted with a Cronus elephant trunk stent (diameter 26 or $28 \mathrm{~mm}$, length 100 or $120 \mathrm{~mm}$; Cronus, MicroPort Endovascular Shanghai Co., Ltd., Shanghai, China). The aortic balloon that fits the diameter of the elephant trunk stent graft, as well as the descending aorta that the graft sticks to ( $40 \mathrm{~mL}$, Coda Balloon Catheter, Cook Incorporated, Bloomington, IN), was then deployed and inflated at the metal part of the stent graft. The aortic balloon also passed through a solid Gore sheath (16 or 18F W.L. Gore \& Associates, Inc., Flagstaff, AZ) that was simultaneously held by hand and exerted sufficient force to counter the retrograde femoral perfusion when it started. The metal part of the stent elephant trunk could protect against injury of the aortic wall (because it is frail due to dissection or connective tissue disorders) as well as produce the static friction needed for the inflated aortic balloon. The lower body circulation resumed after this set up and endto-end anastomosis of the aorta with a tetrafurcated graft (Terumo, Vascutek Limited, Renfrewshire, Scotland, UK) was performed under continuous perfusion. In the conventional method, the nasopharyngeal temperature must reach $26{ }^{\circ} \mathrm{C}$ or lower and anastomosis was performed during lower-body CA. Rewarming of the patient could be started when the common carotid artery was reconstructed and perfusion to both hemispheres was achieved [Fig. 1A-C].

The procedure is highly feasible and safe because the aortic balloon we used fits the diameter of the elephant trunk stent. When we inflate the balloon adequately in the descending aorta, it is simultaneously held in the solid Gore sheath to exert sufficient force to counter the femoral perfusion. The metal part of the elephant trunk stent could produce the static friction for the aortic balloon as well as prevent injury of the aortic wall. However, a larger amount of retrograde back flow from femoral perfusion may occur due to the large false lumen of the descending aorta. During our prior exploration, we learned first to use strong extra cardiac suction to vent the blood back to the cardiopulmonary bypass $(\mathrm{CPB})$ circulation. If an even larger amount of back flow persisted, we correspondingly decreased the lower-body flow to create a clear surgical field, which is one of the reasons we set the target nasal temperature a relatively safe level $\left(28^{\circ} \mathrm{C}\right)$. In a few patients, we explored bilateral cerebral perfusion (both branched from the upper arterial cannula) to the right axillary artery and left common carotid artery, in which case, the target nasal temperature was set at $30{ }^{\circ} \mathrm{C}$ and $\mathrm{CPB}$ flow was set at $2 / 3$ of total flow during the $\mathrm{ABO}$ so that both hemispheres had sufficient perfusion.

\section{Statistical analysis}

The preoperative baseline characteristics and early outcomes were recorded according to the consensus statement from the International Aortic Arch Surgery Study Group [14]. Data from the blood examination were collected at the different time points to depict the trajectories of each examination as well as include them in the multivariate analysis.

The continuous variables are presented as median (lower quartile [Q1], upper quartile [Q3]), except for the quantity of blood transfusion, which is presented as mean \pm standard deviation (SD). For univariate comparison, the normally distributed continuous variable $(\mathrm{P}>0.05$ in the Shapiro-Wilk test) was evaluated with the Student's t-test. The non-normally distributed continuous variable $(\mathrm{P}<0.05$ in the Shapiro-Wilk test) was evaluated with the Mann-Whitney $U$ test, and categorical variables were compared using the $\mathrm{X} 2$ test. Binary logistic regression was performed on clinical 

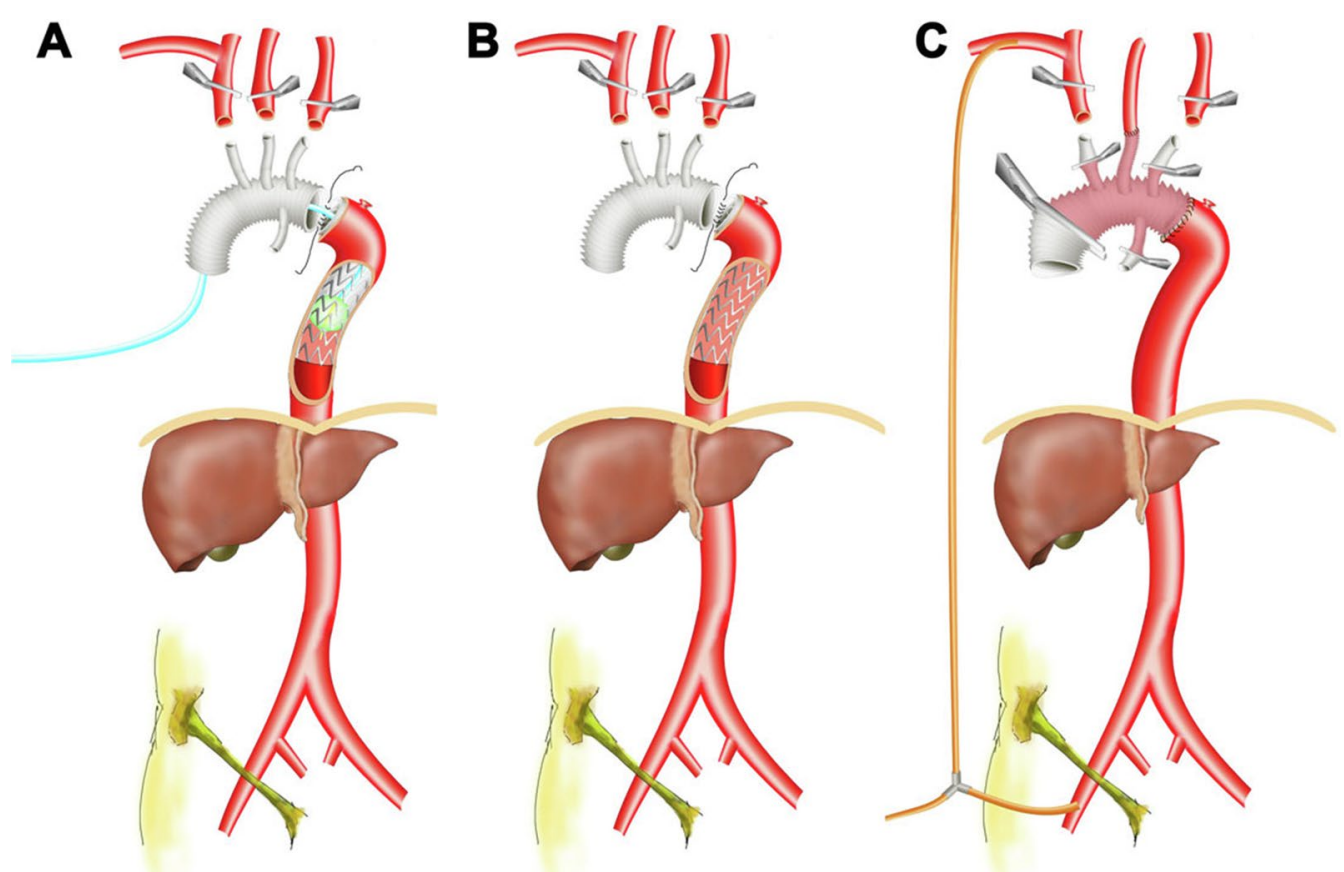

Fig. 1 Illustration of surgical technique TAR with FET. A ABO. B Conventional TAR with FET technique. C Aortic reconstruction before rewarming. The standard cases were performed with right axillary cannulation for unilateral antegrade selective cerebral perfusion with femoral cannulation for retrograde systemic perfusion

outcomes and the requirement of blood transfusion with the reasonable risk factors and checked for Hosmer-Lemeshow fitness before drawing conclusions. If the Hosmer-Lemeshow fitness failed, some risk factors were removed from consideration to make the fitness more than 0.05 . Similar potentially overlapping factors could not be considered in the same comparison, so we picked only one in each model, such as being in the acute stage of aortic dissection (AD) $(<7$ days of symptom onset) or being an emergency operation (surgery performed on admission day or next morning if admission at night), requiring longer postoperative conscious revival time or longer mechanical ventilation time, percentage of neutrophil and neutrophil count, and so on. We used total abdominal aorta involvement, which stands for AD reaching the distal end of the abdominal aorta with or without iliac involvement, to reflect the extension of $\mathrm{AD}$ on clinical results. As a result, the number of factors considered for each comparison did not exceed 32, which is reasonable because statistics suggests fewer than $1 / 10$ of the cases (36 in our model). The statistical analysis was performed using SPSS (version 19.0, IBM-SPSS Inc, Armonk, NY).

\section{Results}

Patient baseline characteristics

Table 1 shows the preoperative and operative details. The median age of the $\mathrm{ABO}$ group and conventional operation group were $51(42-58)$ and $47(40-55)$ years and included $76.2 \%$ and $75.2 \%$ male patients, respectively. The patients had similar smoking history $(56.9 \%$ vs. $56.5 \%)$, cardiovascular disease history $(10.0 \%$ vs. $10.4 \%)$, and stroke history ( $8.5 \%$ vs. $10.0 \%)$. The most common indication for surgery was AD $(94.6 \%$ vs. $96.1 \%)$ that occurred in the acute stage $(76.2 \%$ vs. 78.7\%). The aortic involvement was also similar, with the aortic arch (total or distal part only) at $100 \%$, the aortic root at $43.1 \%$ and $42.1 \%$ proximally and either or both iliac arteries at $59.4 \%$ and $61.1 \%$ distally. Total arch replacement was performed on some patients with a thoracic endovascular aortic repair history due to proximal endoleak despite AD not involving a total aortic arch; the protocol was described in previous research [15]. With the $\mathrm{ABO}$ approach, the duration of lower-body CA was significantly shorter (5 [3-7] $\mathrm{min}$ vs. $17[14-20] \mathrm{min}, \mathrm{P}<0.001)$, with $\mathrm{CA}$ temperature rising from $25.4(24.9-26.0){ }^{\circ} \mathrm{C}$ to $27.6(27.1-28.0){ }^{\circ} \mathrm{C}$ accordingly $(\mathrm{P}<0.001)$. 
Table 1 Preoperative and operative details of consecutive patients who underwent TAR with FET technique

\begin{tabular}{|c|c|c|c|c|}
\hline Variables & $\begin{array}{l}\text { ABO } \\
(n=130)\end{array}$ & $\begin{array}{l}\text { Conventional } \\
(n=230)\end{array}$ & Statistics & $P$ \\
\hline \multicolumn{5}{|l|}{ Preoperative and operative details (contribution to EuroSCORE) } \\
\hline Age (years $\ddagger)$ & $51(42-58)$ & $47(40-55)$ & $1.720^{*}$ & 0.087 \\
\hline Female $(+1)$ & $31(23.9)$ & $57(24.8)$ & $0.039^{*}$ & 0.843 \\
\hline COPD history $(+1)$ & $6(4.6)$ & $2(0.9)$ & $5.363^{*}$ & 0.021 \\
\hline Peripheral arterial disease history $(+2)$ & $11(8.5)$ & $13(5.7)$ & $1.054^{*}$ & 0.503 \\
\hline Stroke history $(+2)$ & $11(8.5)$ & $23(10.0)$ & $0.230^{*}$ & 0.632 \\
\hline Cardiac surgery history $(+3)$ & $2(1.5)$ & $15(6.5)$ & $4.584^{*}$ & 0.032 \\
\hline Preoperative Scr ( $\mu \mathrm{mol} / \mathrm{L})$ & $83.1(71.7-105.8)$ & $90.0(71.7-114.3)$ & Non-normally distributed ${ }^{\dagger}$ & 0.532 \\
\hline $\mathrm{Scr}>200 \mu \mathrm{mol} / \mathrm{L}(+2)$ & $1(0.8)$ & $6(2.6)$ & $1.474^{*}$ & 0.225 \\
\hline $\operatorname{LVEF}(\% \|)$ & $51(47-55.3)$ & $50.5(46-54)$ & Non-normally distributed ${ }^{\dagger}$ & 0.187 \\
\hline Myocardial infarction in 90 days $(+2)$ & $9(6.9)$ & $11(4.8)$ & $0.725^{*}$ & 0.394 \\
\hline Pulmonary hypertension $(+2)$ & $1(0.8)$ & $3(1.3)$ & $0.216^{*}$ & 0.642 \\
\hline $\begin{array}{l}\text { Emergency, operated on the day or next day upon admis- } \\
\text { sion }(+2)\end{array}$ & 93 (71.5) & $174(75.7)$ & $0.734^{*}$ & 0.392 \\
\hline Concomitant coronary artery bypass graft $(+2)$ & $18(13.9)$ & $30(13.0)$ & $0.046^{*}$ & 0.830 \\
\hline EuroSCORE & $2(3-4)$ & $2(3-4)$ & Non-normally distributed ${ }^{\dagger}$ & 0.485 \\
\hline \multicolumn{5}{|l|}{ Other preoperative details } \\
\hline Weight (kg) & $75(67.5-86)$ & $75(67.1-85)$ & Non-normally distributed ${ }^{\dagger}$ & 0.839 \\
\hline Height (cm) & $172(169-176)$ & $172(167-176)$ & Non-normally distributed ${ }^{\dagger}$ & 0.738 \\
\hline Heavy smoker & $74(56.9)$ & $130(56.5)$ & $0.005^{*}$ & 0.941 \\
\hline CAD history & $13(10.0)$ & $24(10.4)$ & $0.017^{*}$ & 0.896 \\
\hline Aortic pathology & & & $0.424^{*}$ & 0.515 \\
\hline Aneurysm & $7(5.4)$ & $9(3.9)$ & & \\
\hline Aortic dissection & $123(94.6)$ & $221(96.1)$ & & \\
\hline Thoracic endovascular aortic repair history & $10(7.7)$ & $13(5.7)$ & $0.578^{*}$ & 0.447 \\
\hline \multicolumn{5}{|l|}{ Aortic dissection involvement } \\
\hline Root & $53(43.1)$ & $93(42.1)$ & $0.033^{*}$ & 0.856 \\
\hline Ascending & $105(85.4)$ & $208(94.1)$ & $7.381^{*}$ & 0.007 \\
\hline Arch & $123(100)$ & $221(100)$ & / & / \\
\hline Total/ proximal & $116(94.3)$ & $217(98.2)$ & $3.845^{*}$ & 0.050 \\
\hline Left subclavian artery or distal & $7(5.7)$ & $4(1.8)$ & & \\
\hline Thoracic descending & $115(93.5)$ & $207(93.7)$ & $0.004^{*}$ & 0.951 \\
\hline Abdominal & $99(80.5)$ & $196(88.7)$ & $4.350^{*}$ & 0.037 \\
\hline Iliac & $73(59.4)$ & $135(61.1)$ & $0.100^{*}$ & 0.752 \\
\hline \multicolumn{5}{|l|}{ Classification based on chronicity } \\
\hline Acute $(<7 \mathrm{~d})$ & $87(66.9)$ & $168(73.0)$ & $1.506^{*}$ & 0.220 \\
\hline Subacute(7-30 d) & $23(17.7)$ & $20(8.7)$ & $6.392^{*}$ & 0.011 \\
\hline Chronic(>30 d) & $20(15.4)$ & $42(18.3)$ & $0.482^{*}$ & 0.488 \\
\hline \multicolumn{5}{|l|}{ Operative details } \\
\hline Operation time (min) & $379(337-430)$ & $395(330-463)$ & Non-normally distributed ${ }^{\dagger}$ & 0.445 \\
\hline CPB time (min) & $175(148-201)$ & $162(141-209)$ & Non-normally distributed ${ }^{\dagger}$ & 0.152 \\
\hline Clamp (min) & $114(94-143)$ & $109(89-131)$ & Non-normally distributed ${ }^{\dagger}$ & 0.034 \\
\hline CA time (min) & $5(3-7)$ & $17(14-20)$ & Non-normally distributed $^{\dagger}$ & $<0.001$ \\
\hline Require secondary CPB & $5(3.85)$ & $29(12.61)$ & $7.457^{*}$ & 0.006 \\
\hline \multicolumn{5}{|l|}{ Temperature change $\left({ }^{\circ} \mathrm{C}\right)$} \\
\hline Nasal temperature during $\mathrm{CA}$ & $27.6(27.1-28.0)$ & $25.4(24.9-26.0)$ & Non-normally distributed ${ }^{\dagger}$ & $<0.001$ \\
\hline Rectal temperature during $\mathrm{CA}$ & $28.7(28-29.7)$ & $28.1(26.7-30.1)$ & Non-normally distributed ${ }^{\dagger}$ & 0.015 \\
\hline
\end{tabular}

Data are presented as median (Q1-Q3) or $n(\%)$

COPD Chronic obstructive pulmonary disease, EuroSCORE European System for Cardiac Operative Risk Evaluation, LVEF left ventricular ejection fractions, SCr serum creatinine, $C A$ circulatory arrest, $C P B$ cardiopulmonary bypass 
Table 1 (continued)

${ }^{*} t$ value; $t: x^{2}$ value; $\neq$ EuroSCORE +1 for 60 years and +1 for every 5 years beyond 60 ; $\S$ EuroSCORE +2 for preoperative serum creatinine more than $200 \mu \mathrm{mol} / L$; ||EuroSCORE +1 for between 30 and $50 \%$ and +3 for less than $30 \%$

\section{In-hospital outcomes}

Postoperative details and early clinical outcomes are listed in Table 2. Univariate comparison showed that 30-day mortality of the $\mathrm{ABO}$ group and conventional operation group were $4.6 \%$ and $7.8 \%$, respectively $(\mathrm{P}=0.241)$. The $\mathrm{ABO}$ group had fewer incidences of prolonged mechanical ventilation $(>72 \mathrm{~h})$, severe lung infection, hepatic injury, and acute kidney injury (AKI). Length of intensive care unit (ICU) stay and postoperative in-hospital stay was similar as well. Despite that the European System for Cardiac Operative Risk Evaluation (EuroSCORE) for both groups was 3 (2 to 4$)(\mathrm{P}=0.485)$, several differences exist. The $\mathrm{ABO}$ group was older, with much less secondary cardiac surgery history, difference in $\mathrm{AD}$ involvement, and unevenly distributed $\mathrm{CPB}$ time. The aorta cross-clamp periods of $\mathrm{ABO}$ were longer (114 [94-143] min vs. 109 [89-131] $\mathrm{min}, \mathrm{P}=0.034$ ) but less secondary $\mathrm{CPB}$ was performed $(3.9 \%$ vs. $12.6 \%$, $\mathrm{P}=0.006)$. Multivariate analysis was performed to find detailed risk factors for each clinical outcome in all consecutive cases. Risk factors for 30-day mortality were heavy smoker (odds ratio, OR, 10.898), chronic obstructive pulmonary disease (COPD) history (OR 10.198), emergency operation (OR 63.887), preoperative percentage of neutrophils (OR 1.123 per \%), and CPB time (OR 1.010 per min) [Table 3].

\section{Renal system risk factors}

Postoperative AKI was defined as serum creatinine (Scr) increased by more than 1.5 times baseline values, which was Scr $>200 \mu \mathrm{mol} / \mathrm{L}$. Being in the conventional group was a risk factor for AKI (OR 2.493), which reflected that longer lower body CA, increased AKI. Higher preoperative hemoglobin was also a risk factor for AKI (OR 1.044 per $\mathrm{g} / \mathrm{L})$, which suggested that the relatively lowered operative hemoglobin content during $\mathrm{CPB}$ could not be well tolerated by the kidneys. Both factors reflected the perfusion operative status of the kidney, which suggested that Scr was a very sensitive indicator of the operative renal perfusion. The magnitude of the operative platelet-counts' decrease was reported to correlate with the severity of AKI in previous research $[16,17]$. In our analysis, higher platelet counts preoperatively (OR 0.922 per $109 / \mathrm{L}$ ) and postoperatively (OR 0.989 per 109/L) were shown to decrease the incidence of AKI. Creatinine generation is proportional to the body muscle weight, thus higher body weight may increase Scr and the incidence of AKI (OR 1.046 per kg). Continuous renal replacement therapy (CRRT) is the treatment for deteriorating renal injury and patients manifesting oliguria were given CRRT (Table 2). In addition to higher preoperative Scr (OR 1.011 per $\mu \mathrm{mol} / \mathrm{L})$, the risk of requiring CRRT is much higher from longer $\mathrm{CPB}$ time (OR 1.013 per min). If $\mathrm{CPB}$ time becomes excessively long, the kidney will be continuously exposed to a relatively ischemic state, which is bound to increase the need for CRRT. The protective effect of $A B O$ was limited, which failed to deliver statistical significance in reducing the need for CRRT.

\section{Hepatic system risk factors}

Hepatic injury is defined as hepatic transaminase increased by $>1.5$ times baseline values for $48 \mathrm{~h}$. We recorded the trajectories of alanine transaminase (ALT) and aspartate aminotransferase (AST) in Fig. 2. AST was considerably higher in the first 3 postoperative days and fell to normal range before discharge. ALT rose steadily rise in the $\mathrm{ABO}$ group. ALT and AST were very sensitive in reflecting lower body perfusion. The levels of ALT and AST were much higher in the conventional group, making presence in that group an independent risk factor for hepatic injury (OR 2.326). Our results showed that AST was much more sensitive than ALT, similar to previous findings [18-20]. Preoperative AST, but not ALT, is an independent risk factor for hepatic injury (OR 1.031). Acute hepatic injury was also risked from longer CPB time (OR 1.008 per min) and higher postoperative Scr (OR 1.010 per $\mu \mathrm{mol} / \mathrm{L}$ ). The partial overlap of acute hepatic injury and AKI suggested that they both posed risks from insufficient lower-body perfusion but manifested in different subpopulations due to differences in other innate risk factors. The liver is the source of blood coagulation factors, which would explain why a higher AST level was related to an increase in red blood cell $(\mathrm{RBC})$ and plasma transfusion requirements [Additional file 1: Table 1].

The AST level must have recovered to a normal range before discharge. Unlike AST, the ALT level tended to grow progressively, although some patients experienced fluctuating levels in the first 3 postoperative days. The ALT level became higher than the preoperative value before discharge. This slow and steady elevation of ALT suggested that it reflected the mid-term sub-acute hepatic injury. Sub-acute hepatic injury is less likely to appear in female patients (OR 0.317). A higher AST level on postoperative day 1 , which is the indicator for acute hepatic injury, is negatively related to sub-acute hepatic injury (OR 0.996 per U/L). 
Table 2 Postoperative details and early clinical outcomes of consecutive patients who underwent TAR with FET technique

\begin{tabular}{|c|c|c|c|c|}
\hline Variables & $A B O(n=130)$ & Conventional $(n=230)$ & Statisticst & $\mathbf{P}$ \\
\hline 30-day mortality & $6(4.6)$ & $18(7.8)$ & 1.376 & 0.241 \\
\hline Conscious revival (h) & $8.1(4.9-13.8)$ & $11.8(7.8-19.0)$ & non-normally distributed & $<0.001$ \\
\hline Delayed conscious revival (> 12 h) & $38(29.2)$ & $103(44.8)$ & 8.431 & 0.004 \\
\hline Mechanical ventilation (h) & $18.7(13.3-36.9)$ & $21.5(13.5-47.0)$ & non-normally distributed & 0.217 \\
\hline Prolonged mechanical ventilation ( $>72 \mathrm{~h}$ ) & $11(8.5)$ & $42(18.3)$ & 6.535 & 0.012 \\
\hline ICU stay $(h)$ & $90.5(59.3-132.8)$ & $86.4(58.7-134.2)$ & non-normally distributed & 0.380 \\
\hline Postoperative in-hospital stay (d) & $11(8-14)$ & $11(9-14)$ & non-normally distributed & 0.321 \\
\hline Postoperative serum creatinine (day 1) & $107.4(85.8-137.8)$ & $168.2(69.7-202.8)$ & non-normally distributed & 0.002 \\
\hline AKI (serum creatinine $>200$ mol/L) & $30(23.1)$ & $82(35.7)$ & 6.128 & 0.013 \\
\hline Oliguria or anuria & $10(7.7)$ & $22(9.1)$ & 0.360 & 0.549 \\
\hline Continuous renal replacement therapy & $10(7.7)$ & $23(10.0)$ & 0.531 & 0.466 \\
\hline Stroke & $4(3.1)$ & $9(3.9)$ & 0.167 & 0.683 \\
\hline Temporal paraplegia & $3(2.3)$ & $10(4.4)$ & 0.993 & 0.319 \\
\hline Delirium & $4(3.1)$ & $15(6.3)$ & 1.972 & 0.160 \\
\hline Acute hepatic injury & $16(12.3)$ & $64(27.8)$ & 11.572 & 0.001 \\
\hline Sub-acute hepatic injury & $55(42.3)$ & $85(37.0)$ & 1.001 & 0.317 \\
\hline Platelet rebound $\neq$ & $90(69.3)$ & $190(82.6)$ & 8.600 & 0.003 \\
\hline Severe lung infection & $3(2.3)$ & $18(7.8)$ & 4.604 & 0.032 \\
\hline $\begin{array}{l}\text { Total chest tube drainage of 0-3 postoperative } \\
\text { day }(\mathrm{mL}) \S\end{array}$ & $1040(720-1260)$ & $1140(860-1460)$ & non-normally distributed & 0.002 \\
\hline Percentage of $>1500 \mathrm{~mL}$ & $18(13.9)$ & $53(23.0)$ & 4.438 & 0.035 \\
\hline Operation day & $380(280-480)$ & $460(360-685)$ & non-normally distributed & 0.760 \\
\hline Postoperative day 1 & $250(200-330)$ & $330(240-450)$ & non-normally distributed & 0.001 \\
\hline Postoperative day 2 & $170(110-240)$ & $225(160-310)$ & non-normally distributed & $<0.001$ \\
\hline Postoperative day 3 & $160(80-230)$ & $190(135-270)$ & non-normally distributed & $<0.001$ \\
\hline Cost of medical bill (USD) & $25,463(21,889-29,627)$ & $24,914(22,077-29,378)$ & non-normally distributed & 0.298 \\
\hline Less than 20,000 & $10(7.7)$ & $24(10.4)$ & 0.903 & 0.637 \\
\hline 20,000 to 30,000 & $89(68.5)$ & $157(68.3)$ & & \\
\hline More than 30,000 & $31(23.9)$ & $49(21.3)$ & & \\
\hline \multicolumn{5}{|c|}{ Blood product transfusion (expressed as percentage of usage and average quantity among used) } \\
\hline Red blood cell transfusion $(U)$ & $\begin{array}{l}7.8 \pm 6.7 \\
83(63.9)\end{array}$ & $\begin{array}{l}8.5 \pm 8.7 \\
174(75.7)\end{array}$ & $\begin{array}{l}\text { non-normally distributed } \\
(5.668)\end{array}$ & $\begin{array}{l}0.581 \\
(0.017)\end{array}$ \\
\hline Intraoperative & $\begin{array}{l}4.8 \pm 3.1 \\
55(42.3)\end{array}$ & $\begin{array}{l}5.9 \pm 4.9 \\
117(50.9)\end{array}$ & $\begin{array}{l}\text { non-normally distributed } \\
(2.440)\end{array}$ & $\begin{array}{l}0.259 \\
(0.118)\end{array}$ \\
\hline During CPB & $\begin{array}{l}4.4 \pm 1.9 \\
43(33.1)\end{array}$ & $\begin{array}{l}4.8 \pm 2.6 \\
78(33.9)\end{array}$ & $\begin{array}{l}\text { non-normally distributed } \\
(0.026)\end{array}$ & $\begin{array}{l}0.612 \\
(0.872)\end{array}$ \\
\hline After CPB & $\begin{array}{l}3.6 \pm 3.2 \\
21(16.2)\end{array}$ & $\begin{array}{l}4.9 \pm 4.3 \\
65(28.3)\end{array}$ & $\begin{array}{l}\text { non-normally distributed } \\
\text { (6.696) }\end{array}$ & $\begin{array}{l}0.056 \\
(0.010)\end{array}$ \\
\hline Postoperative & $\begin{array}{l}5.9 \pm 4.8 \\
65(50.0)\end{array}$ & $\begin{array}{l}6.0 \pm 7.1 \\
132(57.4)\end{array}$ & $\begin{array}{l}\text { non-normally distributed } \\
(1.831)\end{array}$ & $\begin{array}{l}0.741 \\
(0.176)\end{array}$ \\
\hline Plasma transfusion (ml) & $\begin{array}{l}770.7 \pm 549.0 \\
82(63.1)\end{array}$ & $\begin{array}{l}997.2 \pm 856.6 \\
141(61.3)\end{array}$ & $\begin{array}{l}\text { non-normally distributed } \\
(0.111)\end{array}$ & $\begin{array}{l}0.011 \\
(0.739)\end{array}$ \\
\hline Intraoperative & $\begin{array}{l}550.7 \pm 392.0 \\
71(54.6)\end{array}$ & $\begin{array}{l}675.8 \pm 369.2 \\
124(53.9)\end{array}$ & $\begin{array}{l}\text { non-normally distributed } \\
(0.017)\end{array}$ & $\begin{array}{l}0.001 \\
(0.898)\end{array}$ \\
\hline Postoperative & $\begin{array}{l}573.8 \pm 406.7 \\
42(32.3)\end{array}$ & $\begin{array}{l}778.0 \pm 798.3 \\
73(31.7)\end{array}$ & $\begin{array}{l}\text { non-normally distributed } \\
(0.012)\end{array}$ & $\begin{array}{l}0.153 \\
(0.912)\end{array}$ \\
\hline Platelets transfusion $(U)$ & $\begin{array}{l}1.5 \pm 0.9 \\
102(78.6)\end{array}$ & $\begin{array}{l}1.7 \pm 1.5 \\
189(82.2)\end{array}$ & $\begin{array}{l}\text { non-normally distributed } \\
(0.739)\end{array}$ & $\begin{array}{l}0.338 \\
(0.390)\end{array}$ \\
\hline Intraoperative & $\begin{array}{l}1.2 \pm 0.5 \\
93(71.5)\end{array}$ & $\begin{array}{l}1.2 \pm 0.9 \\
172(74.8)\end{array}$ & $\begin{array}{l}\text { non-normally distributed } \\
(0.450)\end{array}$ & $\begin{array}{l}0.734 \\
(0.502)\end{array}$ \\
\hline Postoperative & $\begin{array}{l}2.2 \pm 1.2 \\
18(13.9)\end{array}$ & $\begin{array}{l}2.2 \pm 2.0 \\
51(22.2)\end{array}$ & $\begin{array}{l}\text { non-normally distributed } \\
(3.718)\end{array}$ & $\begin{array}{l}0.304 \\
(0.054)\end{array}$ \\
\hline
\end{tabular}


Table 2 (continued)

\begin{abstract}
$A B O$ Aortic balloon occlusion, TAR total aortic arch replacement, $F E T$ frozen elephant trunk, CPB cardiopulmonary bypass, USD United States dollar, AKI acute kidney injury

*Data are expressed as median (Q1-Q3) or $n(\%)$, except for the quantity of blood transfusion, which is presented as mean \pm standard deviation

${ }^{\dagger}$ Statistical values for normally distributed continuous variable is $t$ value, for categorical variables is $x 2$ value, or is noted as non-normally distributed continuousvariable

‡ Platelet rebound stands for the last re-examination of platelet count during in hospital stay was higher than the preoperative level

${ }^{5}$ Total chest tube drainage of 0-3 postoperative day (per $100 \mathrm{~mL}$ ) was considered in the multivariable analysis for postoperative bleeding as it is a direct factor for blood loss
\end{abstract}

\section{Nervous system risk factors}

The risk factors for most clinical outcomes could be established, except for postoperative stroke and temporary paraplegia, which were relatively lower than other clinical adverse outcomes and could only be compared with a larger number of patients. If we loosened the $\mathrm{P}$ value from $<0.05$ to $<0.1$, temporary paraplegia was a positive risk from total abdominal aorta involvement and preoperative Scr, both of which suggested that a longer extension of $\mathrm{AD}$ and possibly more segmental branches of the aorta supplying the spinal cord were involved. The postoperative conscious revival time from anesthesia was significantly shortened by application of $A B O$. Even though both groups received continuous cerebral perfusion, the nadir nasal temperature was lower with significantly longer cooling and rewarming time in the conventional group, which made being in that group a risk factor for prolonged conscious revival time $(>12 \mathrm{~h}$ ) (OR 2.521). Older age (OR 1.048 per year) and female gender (OR 2.512) also tended to delay conscious revival. Most anesthetics metabolized through the liver and some through the kidney, which partially explained why the factors of preoperative ALT (OR 1.011 per U/L), postoperative Scr (OR 1.007 per $\mu \mathrm{mol} / \mathrm{L}$ ), and greater weight (because more anesthetics were used, OR 1.027 per $\mathrm{kg}$ ) increased the risk of delayed conscious revival. The patient had to revive from anesthesia before withdrawal of mechanical ventilation. Even if the patient revived earlier, longer mechanical ventilation time could increase the risk of delirium (OR 1.033), a status of incomplete of consciousness that would require antipsychotics. It could be partially explained by cerebral hypoxia observed in previous research [21]. Higher postoperative fibrinogen degradation product (FDP) was also a risk for delirium (OR 1.067).

\section{Respiratory system risk factors}

Prolonged mechanical ventilation was solely risked from longer $\mathrm{CPB}$ time (OR 1.011 per $\mathrm{min}$ ). Longer $\mathrm{CPB}$ meant more operative damage and more compromised immune system which would be more susceptible to severe inflammation. Severe lung infection meant prolonging mechanical ventilation despite prolonged strong antibiotics usage, in which situation surgical or endoscopic intervention was required. Its risk factor included patients' basic lung function (heavy smoker, OR 80.126; and COPD history, OR 48.864), as well as longer CPB time (OR 1.014 per min). Higher postoperative Scr (OR 1.011 per $\mu \mathrm{mol} / \mathrm{L}$ ) posed a risk for severe lung infection, although $\mathrm{ABO}$ did not directly relate to severe lung infection.

\section{Blood routine tests and transfusion risk factors}

Total leukocyte count and neutrophil/lymphocyte ratio (NLR), which are inflammatory indicators, are represented in Fig. 3A, B. Multivariate analysis showed a higher preoperative total leukocyte or neutrophil count was a risk factor for AKI, CRRT, hepatic injury, and 30-day mortality.

Blood hemoglobin was at similar levels in both groups preoperatively. During CPB, both groups received similar quantities of RBC transfusion, suggesting that blood loss due to the continuation of $\mathrm{CPB}$ was similar. After $\mathrm{CPB}$ during the operation, the $\mathrm{ABO}$ group required much less $\mathrm{RBC}$ transfusion. As a result, $\mathrm{ABO}$ reduced total $\mathrm{RBC}$ usage [Fig. 3C and Table 2].

Univariate comparisons were not accurate because many other factors affected transfusion. Multivariate analysis was performed on events if transfusion of RBC, plasma, or platelet was required ( $>0$ package) and if the requirement for transfusion was large (reached or was more than 3 packages, $6 \mathrm{U}$ of RBC, $600 \mathrm{~mL}$ of plasma, or $3 \mathrm{U}$ of platelet). The result showed that cardiac surgery history was a risk factor for operative RBC transfusion (OR 7.703) and large operative RBC transfusion (OR 8.760). Female gender, older age, emergency operation, higher preoperative leukocyte or neutrophil count, postoperative mechanical ventilation time, and longer $\mathrm{CPB}$ time were risk factors that increased $R B C$ transfusion. Being in the conventional group was a risk factor for large operative RBC transfusion after CPB (OR 25.520) but not during $\mathrm{CPB}$, large total operative $\mathrm{RBC}$ transfusion (OR 3.554), and large total $\mathrm{RBC}$ transfusion during the inhospital stay (OR 2.134). Large postoperative transfusion was also risked from postoperative AST (OR 1.004 per $\mathrm{U} / \mathrm{L}$ ) and postoperative Scr (OR 1.011 per $\mu \mathrm{mol} / \mathrm{L})$, suggesting that large transfusion may be the cause or caused from postoperative hepatic injury or AKI. ABO did not 
Table 3 Multivariable analysis of risk factors for clinical outcomes

\begin{tabular}{|c|c|c|c|}
\hline Risk factors (Hosmer-Lemeshow fitness*) & Odds ratio & $95 \%$ confidence interval & $P$ \\
\hline \multicolumn{4}{|l|}{ 30-day mortality (0.189) } \\
\hline Heavy smoker & 10.898 & $1.974-60.151$ & 0.006 \\
\hline COPD history & 10.198 & $1.096-94.915$ & 0.041 \\
\hline Emergency operation & 63.887 & $4.828-845.303$ & 0.002 \\
\hline Preoperative leukocyte count $\left(10^{9} / \mathrm{L}\right)$ & $(1.109)$ & $(0.942-1.305)$ & $(0.213)$ \\
\hline Preoperative percentage of neutrophils (\%) & 1.123 & $1.020-1.237$ & 0.018 \\
\hline CPB time (min) & 1.010 & $1.005-1.015$ & $<0.001$ \\
\hline \multicolumn{4}{|l|}{ Continuous renal replacement therapy (0.401) } \\
\hline COPD history & 7.965 & $1.079-58.783$ & 0.042 \\
\hline Emergency operation & 7.972 & $1.003-58.709$ & 0.049 \\
\hline Preoperative Scr ( $\mu \mathrm{mol} / \mathrm{L})$ & 1.011 & $1.001-1.021$ & 0.028 \\
\hline Preoperative leukocyte count $\left(10^{9} / \mathrm{L}\right)$ & 1.191 & $1.015-1.399$ & 0.032 \\
\hline Preoperative percentage of neutrophils (\%) & $(0.983)$ & $(0.920-1.050)$ & $(0.614)$ \\
\hline Preoperative D-dimer $(\mu \mathrm{g} / \mathrm{ml})$ & 1.088 & $1.007-1.017$ & 0.032 \\
\hline CPB time $(\min )$ & 1.013 & $1.008-1.018$ & $<0.001$ \\
\hline \multicolumn{4}{|l|}{ Acute kidney injury (0.709) } \\
\hline Weight (kg) & 1.046 & $1.006-1.087$ & 0.023 \\
\hline Height $(\mathrm{cm})$ & 0.954 & $0.916-0.993$ & 0.022 \\
\hline Conventional group & 2.493 & $1.025-6.061$ & 0.044 \\
\hline Concomitant CABG & 3.419 & $1.142-10.233$ & 0.028 \\
\hline Preoperative Scr ( $\mu \mathrm{mol} / \mathrm{L})$ & 1.049 & $1.033-1.065$ & $<0.001$ \\
\hline Preoperative hemoglobin (g/L) & 1.044 & $1.010-1.078$ & 0.010 \\
\hline Preoperative platelet count $\left(10^{9} / \mathrm{L}\right)$ & 0.922 & $0.985-0.999$ & 0.032 \\
\hline Postoperative neutrophil count $0+\left(10^{9} / \mathrm{L}\right)$ & 1.200 & $1.081-1.332$ & 0.001 \\
\hline Postoperative platelet count $0\left(10^{9} / \mathrm{L}\right)$ & 0.989 & $0.978-1.000$ & 0.044 \\
\hline \multicolumn{4}{|l|}{ Acute hepatic injury (0.953) } \\
\hline Conventional group & 2.326 & $1.230-4.399$ & 0.009 \\
\hline Preoperative AST (U/L) & 1.031 & $1.005-1.057$ & 0.021 \\
\hline CPB time (min) & 1.008 & $1.003-1.014$ & 0.002 \\
\hline Postoperative platelet count $0\left(10^{9} / \mathrm{L}\right)$ & 0.989 & $0.983-0.996$ & 0.002 \\
\hline Postoperative leukocyte count $0\left(10^{9} / L\right)$ & 1.094 & $1.019-1.176$ & 0.014 \\
\hline Postoperative percentage of neutrophils 0 (\%) & 0.886 & $0.829-0.946$ & $<0.001$ \\
\hline Postoperative Scr ( $\mu \mathrm{mol} / \mathrm{L})$ & 1.010 & $1.004-1.015$ & $<0.001$ \\
\hline \multicolumn{4}{|l|}{ Temporal paraplegia (0.328) } \\
\hline Total abdominal aorta involvement & 10.147 & $0.755-136.293$ & 0.080 \\
\hline Preoperative Scr $(\mu \mathrm{mol} / \mathrm{L})$ & 1.023 & $0.996-1.052$ & 0.099 \\
\hline \multicolumn{4}{|l|}{ Delirium (1.000) } \\
\hline Postoperative mechanical ventilation (h) & 1.033 & $1.010-1.057$ & 0.005 \\
\hline Postoperative FDP $(\mu \mathrm{g} / \mathrm{mL})$ & 1.067 & $1.001-1.136$ & 0.045 \\
\hline \multicolumn{4}{|l|}{ Delayed conscious revival (> 12 h) (0.526) } \\
\hline Age (yrs) & 1.048 & $1.019-1.078$ & 0.001 \\
\hline Weight (kg) & 1.027 & $1.005-1.050$ & 0.015 \\
\hline Conventional group & 2.521 & $1.475-4.309$ & 0.001 \\
\hline Female & 2.512 & $1.108-5.695$ & 0.027 \\
\hline Preoperative ALT (U/L) & 1.011 & $1.001-1.022$ & 0.031 \\
\hline Postoperative Scr ( $\mu \mathrm{mol} / \mathrm{L})$ & 1.007 & $1.000-1.014$ & 0.043 \\
\hline \multicolumn{4}{|l|}{ Prolonged mechanical ventilation (> 72 h) (0.342) } \\
\hline CPB time (min) & 1.011 & $1.006-1.016$ & 0.001 \\
\hline
\end{tabular}


Table 3 (continued)

\begin{tabular}{|c|c|c|c|}
\hline Risk factors (Hosmer-Lemeshow fitness*) & Odds ratio & $95 \%$ confidence interval & $P$ \\
\hline \multicolumn{4}{|l|}{ Severe lung infection (0.714) } \\
\hline Heavy smoker & 80.126 & $2.161-2971.041$ & 0.017 \\
\hline COPD history & 48.864 & $1.337-1786.397$ & 0.034 \\
\hline CPB time (min) & 1.014 & $1.005-1.024$ & 0.002 \\
\hline Postoperative $\operatorname{Scr}(\mu \mathrm{mol} / \mathrm{L})$ & 1.011 & $1.000-1.023$ & 0.049 \\
\hline \multicolumn{4}{|l|}{ Platelet rebound $(0.106)$} \\
\hline Conventional group & 2.046 & $1.130-3.704$ & 0.018 \\
\hline Postoperative platelet count $0\left(10^{9} / \mathrm{L}\right)$ & 0.986 & $0.979-0.992$ & $<0.001$ \\
\hline Postoperative leukocyte count $0\left(10^{9} / \mathrm{L}\right)$ & 1.121 & $1.034-1.215$ & 0.006 \\
\hline Postoperative percentage of neutrophils 0 (\%) & $(0.992)$ & $(0.928-1.060)$ & $(0.809)$ \\
\hline RBC transfusion total $(U)$ & 0.907 & $0.836-0.984$ & 0.019 \\
\hline Plasma transfusion total (ml) & 0.999 & $0.999-1.000$ & 0.038 \\
\hline Final re-exam of platelet count time (d) & 1.163 & $1.086-1.244$ & $<0.001$ \\
\hline \multicolumn{4}{|l|}{ Sub-acute hepatic injury (0.826) } \\
\hline Female & 0.317 & 0.107 to 0.937 & 0.038 \\
\hline Postoperative ALT1§ (U/L) & 1.008 & 1.001 to 1.015 & 0.032 \\
\hline Postoperative AST1 (U/L) & 0.996 & 0.992 to 1.000 & 0.038 \\
\hline \multicolumn{4}{|l|}{ Cost less (<20,000 USD) (0.804) } \\
\hline Total abdominal aorta involvement & 0.250 & $0.109-0.575$ & 0.001 \\
\hline CPB time (min) & 0.978 & $0.965-0.990$ & 0.001 \\
\hline \multicolumn{4}{|l|}{ Cost more (> 30,000 USD) (0.699) } \\
\hline Age (yrs) & 1.034 & $1.001-1.069$ & 0.046 \\
\hline Weight (kg) & 1.033 & $1.006-1.061$ & 0.017 \\
\hline Cardiac surgery history & 6.211 & $1.828-21.103$ & 0.003 \\
\hline Preoperative Scr ( $\mu \mathrm{mol} / \mathrm{L})$ & 1.011 & $1.004-1.019$ & 0.004 \\
\hline Preoperative percentage of neutrophils (\%) & 0.956 & $0.917-0.996$ & 0.031 \\
\hline Preoperative D-dimer $(\mu \mathrm{g} / \mathrm{mL})$ & 1.062 & $1.004-1.124$ & 0.036 \\
\hline CPB time (min) & 1.007 & $1.003-1.011$ & $<0.001$ \\
\hline
\end{tabular}

ALT Alanine transaminase, AST aspartate transaminase, COPD chronic obstructive pulmonary disease, CPB cardiopulmonary bypass, FDP fibrinogen degradation product, $R B C$ red blood cell count, Scrserum creatinine, USD United States dollar, CAD coronary artery disease

* Each multivariable analysis of risk factors can be accepted if the $P$ value of Hosmer-Lemeshow fitness was more than 0.05

${ }^{\dagger}$ All the postoperative blood test 0 stands for the immediate reexamination time point when the operation ended and transferred to ICU

${ }^{\ddagger}$ Platelet rebound stands for the last re-examination of platelet count during in hospital stay was higher than the preoperative level

${ }^{\S}$ All the postoperative blood test 1 stands for the reexamination time point of postoperative day 1

reduce the plasma and platelet transfusion requirements, according to multivariate analysis. Longer CPB time was the most important factor affecting nearly all aspects of blood product transfusion. Longer post-operative mechanical ventilation, cardiac surgery history, female gender, and aortic pathology (total abdominal aorta involvement) were strong factors positively related to blood product transfusion [Additional file 1: Table 1].

\section{Coagulation system risk factors}

The coagulation factors were contained in the plasma. The $\mathrm{ABO}$ group required less plasma transfusion during the operation. Platelet transfusion was similar between the groups [Table 2]. The trajectory of platelet count is shown in Fig. 3D and its pattern is similar to previous researches $[16,22,23]$. During $\mathrm{CPB}$, the platelets were severely diluted and damaged and about $80 \%$ of patients required platelet transfusion to control bleeding from the suturing properly. Even with the plasma and platelet transfusion, the bleeding from the chest tube was still relatively large in the earlier postoperative days [Table 2 and Additional file 1: Fig. 1]. Unlike RBC content, which stayed at a low level after the operation and most patients were still in an anemic state before discharge, the platelet count showed evident rising tendency at some point of the recovery process, which mostly appeared around postoperative day 3. Previous research also observed this phenomenon and argued that this process is indicative 


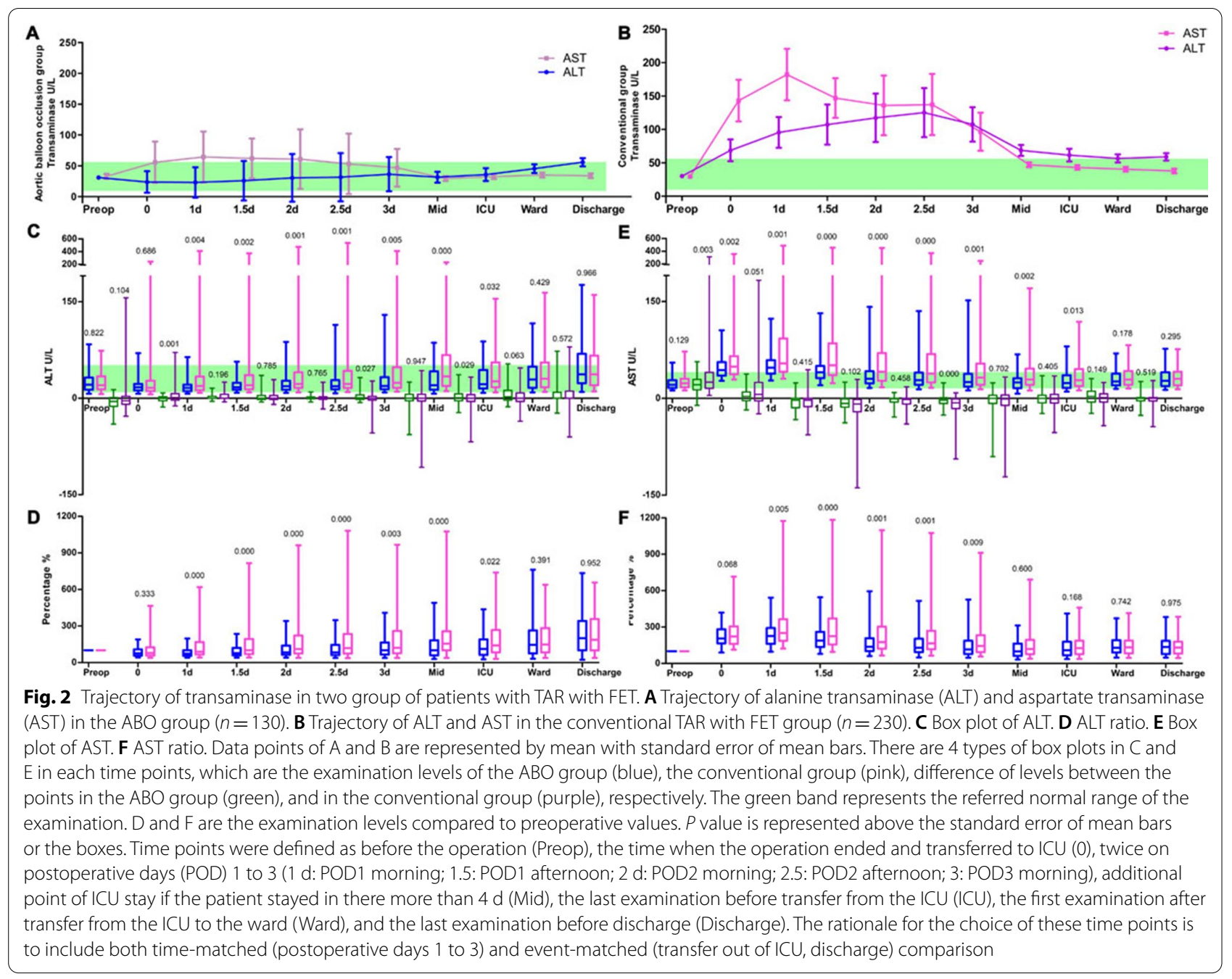

of a persistent platelet activation and aggregation in the first three postoperative days [16, 22, 23]. In the present study, the platelet count delayed to show the rising tendency in the conventional group because those patients experienced a larger quantity of blood loss from the chest tube in the first 3 preoperative days. There were $69.2 \%$ of patients in the $\mathrm{ABO}$ group and $82.6 \%$ in the conventional group $(\mathrm{P}=0.003)$ whose last re-examination of platelet count during in hospital stay was higher than the preoperative level (platelet rebound). Multivariate analysis showed that a higher postoperative platelet count on operation day (0) would reduce the incidence of platelet rebound (OR 0.986 per 109/L) probably due to negative feedback. The later the re-examination of the platelet count is, the higher platelet count would rise (OR 1.163 per day), suggesting its tedency to rise continuously during our observation window. A higher platelet count was also an indication of inflammation; thus, being in the conventional group (OR 2.046) and having a higher leukocyte count (OR 1.121 per 109/L) were also risk factors for persistent platelet activation and aggregation. The final platelet count before discharge was apparently negatively related to the quantity of RBC (OR 0.907 per $\mathrm{U})$ and plasma (OR 0.999 per $\mathrm{mL}$ ) transfusion because they diluted the platelet concentration.

Pre- and postoperative D-dimer and FDP are shown in Additional file 1: Fig. 2. Higher preoperative FDP is a risk factor for RBC transfusion during $\mathrm{CPB}$. Higher postoperative FDP was a risk factor for large platelet $(\geq 3 \mathrm{U})$ transfusion [Additional file 1: Table 1].

\section{Risk factors tended to increase cost}

The overall medical bill for the $\mathrm{ABO}$ group and conventional group was 25.5 (21.9-29.6) vs. 24.9 (22.1-29.4) kUSD, respectively $(\mathrm{P}=0.298)$. Old age (OR 1.034 per year), greater body weight (OR 1.033 per $\mathrm{kg}$ ), cardiac surgery history (OR 6.211), higher preoperative Scr (OR 1.011 per $\mu \mathrm{mol} / \mathrm{L}$ ), higher preoperative $\mathrm{D}$-dimer (OR 


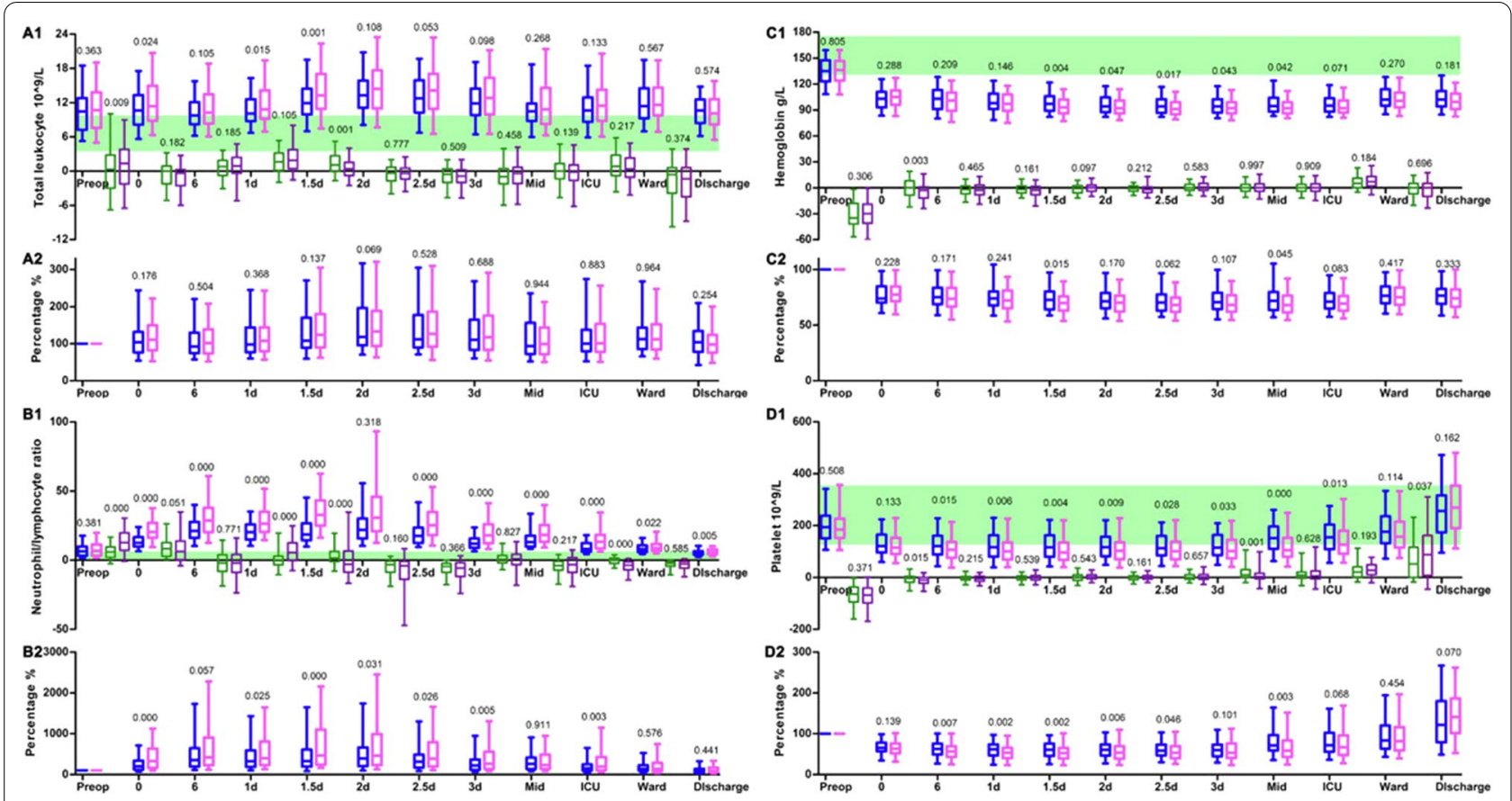

Fig. 3 Blood routine tests of the ABO group $(n=130)$ and the conventional TAR with FET group $(n=230)$. A Leukocyte count: A1, value; A2 ratio. B Neutrophil/lymphocyte ratio: B1, value; B2 ratio. C Hemoglobin: C1, value; C2 ratio. D Platelet count: D1, value; D2 ratio. There are 4 types of box plots in $A 1, B 1, C 1$, and D1 in each time points. $A 2, B 2, C 2$, and $D 2$ are the examination levels compared to preoperative values. $P$ value is represented above the boxes

1.062 per $\mu \mathrm{g} / \mathrm{mL}$ ) and longer $\mathrm{CPB}$ time (OR 1.007 per min) were risk factors for increased cost (>30 kUSD).

\section{Discussion}

The ABO technique is a perfusion strategy of the TAR and FET technique that featured consistently shortened lower-body CA that subsequently raised the target nadir temperature setting point during $\mathrm{CA}$, which provided end-organ protection during the operation. In multivariate analysis, the $\mathrm{ABO}$ technique was shown to prevent postoperative AKI, hepatic injury, delayed conscious revival, and large quantity of $\mathrm{RBC}$ transfusion. Even with the $\mathrm{ABO}$ technique as a protective factor, the TAR with FET still entailed by different risks for serious complication during the routine postoperative course. Although freeing the patient from major complications was the major goal, we usually felt that most postoperative complications occurred randomly and the risk factors behind them were overlooked. Thus we need clear understanding of how the commonly recognized risk factors matched up with different clinical outcomes. Before the operation, we always evaluated whether the patient would benefit more from the operation than suffer from the susceptible risks. The study of the mechanisms of serious complication in the new setting of $\mathrm{ABO}$ would be helpful in the treatment and prevention of complications from aortic operations.
Only a trend showing that $\mathrm{ABO}$ reduced 30-day mortality could not reach statistical significance. We found several risk factors for in-hospital mortality, but the only adjustable factor for the surgeon was longer CPB time and the other innate factors contributed to the incidence of mortality, which the surgeon should be aware of prior to the operation. This result suggests that $\mathrm{CPB}$ time is the most important factor related to an increase in 30-day mortality because it increases the risk by the minute, which outweighs the other factors if the procedure lasts longer. ABO, however, was not significant in terms of reducing mortality. The most important risk factor causing postoperative complications was longer CPB time, affecting nearly all aspects, particularly 30-day mortality and CRRT. Application of ABO decreased the incidence of AKI and hepatic injury and shortened postoperative conscious revival time in the overall population of our cohort, but its effect was limited and might not translate into less 30-day mortality or CRRT. The preoperative Scr level largely reflected the profound development of $\mathrm{AD}$ that might have caused renal malperfusion. A higher preoperative Scr level was one of the risk factors for AKI, need for CRRT, delayed conscious revival, severe lung infection, and increased medical bills. Postoperative Scr level indicated operative damage. Higher postoperative Scr level was one of the risk factors for increased RBC 
and platelet transfusion. Higher postoperative platelet count, which was an indication of less operative damage, was an independent predictor of less AKI and hepatic injury. Although the mutual indication in AKI and platelet count was described in a previous research $[16,17]$, the injury to kidney, liver, and blood cells in our patients were ultimately caused from the operation. During surgery, $\mathrm{ABO}$ could provide more reliable end-organ perfusion and higher temperature which prevented prolonged systemic cooling and rewarming. Such improvements might be crucial in preventing postoperative complications for patients who already carry great risks and are on the margin of developing complications.

The NLR is recognized as a marker of inflammation associated with poor outcomes after cardiac surgery [24] and aortic surgery [25-27]. In terms of postoperative care, neutrophil count would naturally elevate because of the unwanted inflammation resulting from the stimulation of the cardiac surgery and rise even higher if bacterial or fungal infection occurred, but the lymphocyte count, which is the indicator of compromised immune system, would naturally decrease. The lymphocyte count is much lower in frail patients resulting from both their preoperative conditions and the operative damage. The rise of the neutrophil count and fall of lymphocyte count make NLR the much more sensitive indicator of the overall condition of patients in the ICU than any leukocyte count alone does. As a result, the total leukocyte count did not show statistical difference, whereas the NLR rose much higher in the conventional group. Their alteration pattern of total leukocyte count and NLR suggested that their inflammatory status was much more severe in the earlier postoperative days in the ICU because of the acute operative stimulus, but evidently recovered to normal values before discharge. Considering that the preoperative total leukocyte counts were at high levels in both groups, we believe this high leukocyte count was caused by the acute onset of AD; even if the leukocyte count was high, the patients still had to be operated on in this emergency situation.

When CPB started, the bypass prime solution was mixed with the blood of the patient's own circulation, which created the risk of excessive hemodilution. $\mathrm{CPB}$ would then damage $\mathrm{RBC}$ and trigger transfusion if the blood hemoglobin fell below $70 \mathrm{~g} / \mathrm{L}$. After $\mathrm{CPB}$, the $\mathrm{RBC}$ transfusion threshold was $80 \mathrm{~g} / \mathrm{L}$. We followed the $\mathrm{RBC}$ transfusion guideline of $80 \mathrm{~g} / \mathrm{L}$ according to previous research, which suggested that such a lower level could achieve acceptable early outcomes [28]. As a result, the quantity of transfusion is quite large, similar to a previous report [29] and successfully maintained the postoperative blood hemoglobin level. Compared to the relatively slow recovery of hemoglobin, the platelet counts showed a rapid rebound during the ICU stay. In addition to this commonly recognized factor, we found several hemodynamic factors in the multivariate analysis of transfusion. RBC and platelet transfusion was negatively related to the preoperative level of hemoglobin and platelet count, as well as to body mass. Patients with higher weight and more blood cell concentration had more blood cell reserve, and if the operation exerted similar damage to the blood cells, they were less likely to require transfusion. On the contrary, the plasma transfusion requirement was positively related to body mass, because the $\mathrm{CPB}$ could quickly eliminate nearly all blood coagulation factors and the patients who weighted higher required more plasma to replenish coagulation factors. Another hemodynamic factor, total chest tube drainage in postoperative day 1-3 was strongly related to postoperative transfusion blood directly lost from the chest tube.

The most obvious limitation of this study is the inaccurate univariate comparisons for the continuous variables; thus, we also presented the blood examination trajectories with additional figures, in which they were normalized to the preoperative baseline. We only presented the data within only a short time span (since the invention of the technique in Aug 2017). Even with the same standard of postoperative care, differences of preoperative characteristics between the groups weakened the univariate comparisons. The preoperative characteristics also differed from other centers in several aspects; in particular our patients were much younger and had no abdominal malperfusion or preoperative shock, making our results difficult for direct comparison to other centers [30]. In addition, the shorter circulatory arrest (CA) time in the control group may have contributed to the lack of significant differences in some aspects between them and the patients in the $\mathrm{ABO}$ group. Based on the fact that Fuwai Hospital is one of the world's largest centers for cardiac surgery, and its total number of procedures and operating techniques for aortic dissection are at an international advanced level, this is consistent with the $17 \mathrm{~min} \mathrm{CA}$ time of patients in the non-ABO group in this paper, however, the CA time in general hospitals is much longer than $17 \mathrm{~min}$, so this paper would cause selection bias and weaken the differences between the $\mathrm{ABO}$ group and the non-ABO group in various aspects. In the future, it may be possible to observe whether patients who received the $\mathrm{ABO}$ technique have a better prognosis by comparing the differences between the two groups in other hospitals or by performing longterm follow-up of the two groups in our center. 


\section{Conclusions}

Aortic surgery with CA carries greater risks for hepatic, renal, and hematological injury than other routine cardiac operations. The $\mathrm{ABO}$ technique could serve as an important operative protective factor that improves the biochemical tests and the recovery process during in-hospital stay, although it did not translate into less CRRT or mortality. However, each complication was specifically affected by different preoperative and operative factors. Thus, the ABO technique cannot be regarded as the ultimate tool to prevent complications. We still believe that the continuous perfusion that $\mathrm{ABO}$ provided was crucial in diminishing the operative injury for frail or risky patients who might not survive the operation. Identification of the risk factors for adverse clinical outcomes is crucial for improving protocols to optimize perioperative care.

\section{Abbreviations}

ABO: Aortic balloon occlusion; TAR: Total arch replacement; FET: Frozen elephant trunk; HCA: Hypothermic circulatory arrest; ALT: Alanine transaminase; AST: Aspartate transaminase; ICU: Intensive care unit; CA: Circulatory arrest; SD: Standard deviation; RBC: Red blood cell; AD: Aortic dissection; CPB: Cardiopulmonary bypass; FDP: Fibrinogen degradation product; NLR: Neutrophil/lymphocyte ratio; AKI: Acute kidney injury; CRRT: Continuous renal replacement therapy.

\section{Supplementary Information}

The online version contains supplementary material available at https://doi. org/10.1186/s13019-021-01643-3.

Additional file 1. Supplementary Figure 1: Postoperative chest tube output of the ABO group (left column of each point, $n=130$ ) and the conventional TAR with FET group (right column of each point, $n=230$ ). Each bar represents the percentage of chest tube remaining on each postoperative day (\%) and chest tube output is graded by showing different colors. Supplementary Figure 2: Blood coagulation test of the ABO group ( $n=130)$ and the conventional TAR with FET group $(n=230)$. (A) D-dimer. (B) D-dimer ratio. (C) Fibrinogen degradation product. (D) Fibrinogen degradation product ratio. Table S1: Multivariable analysis of blood product transfusion*.

\section{Acknowledgements}

The authors are grateful to all the surgeons in the vascular surgery center for providing the data.

\section{Authors' contributions}

Conception and design: LW and XS; Administrative support: YL; Provision of study materials or patients: YD; Collection and assembly of data: LW; Data analysis and interpretation: LW; Manuscript writing: All authors; Final approval of manuscript: All authors. All authors read and approved the final manuscript.

\section{Funding}

This work was supported by the Beijing Municipal Science and Technology Commission (Z181100001718197).

\section{Availability of supporting data}

The datasets used and/or analyzed during the current study are available from the corresponding author on reasonable request.

\section{Declarations}

Ethics approval and consent to participate

This single-center retrospective cohort study was approved by the ethics committees of the institutional review board of the National Center for Cardiovascular Diseases, Chinese Academy of Medical Sciences and Peking Union Medical College (No. 20180528001) and the written informed consent was waived due to the retrospective design.

\section{Consent for publication}

Consents for publication were obtained from all individuals involved in our study.

\section{Competing interests}

The authors declare that they have no competing interests.

Received: 7 June 2021 Accepted: 29 August 2021

Published online: 08 September 2021

\section{References}

1. Liu ZG, Sun LZ, Chang Q, Zhu JM, Dong C, Yu CT, et al. Should the "elephant trunk" be skeletonized? Total arch replacement combined with stented elephant trunk implantation for Stanford type A aortic dissection. J Thorac Cardiovasc Surg. 2006;131:107-13.

2. Sun L, Qi R, Zhu J, Liu Y, Zheng J. Total arch replacement combined with stented elephant trunk implantation: a new "standard" therapy for type a dissection involving repair of the aortic arch? Circulation. 2011;123:971-8.

3. Wei J, Chen Z, Zhang H, Sun X, Qian X, Yu C. In-hospital major adverse outcomes of acute Type A aortic dissection. Eur J Cardiothorac Surg. 2019:55:345-50.

4. Tian DH, Wan B, Di Eusanio M, Black D, Yan TD. A systematic review and meta-analysis on the safety and efficacy of the frozen elephant trunk technique in aortic arch surgery. Ann Cardiothorac Surg. 2013;2:581-91.

5. Wu HB, Zhang H, Wang ZW, Hu R, Li LC, Zhang M, et al. Surgery for acute aortic dissection using the Chinese CRONUS stentedelephant trunk technique: experience with 252 patients. J Thorac Cardiovasc Surg. 2014;148:2132-8. https://doi.org/10.1016/j.jtcvs.2013.12.007.

6. Ma WG, Zheng J, Sun LZ, Elefteriades JA. Open stented grafts for frozen elephant trunk technique: technical aspects and current outcomes. Aorta (Stamford). 2015;3:122-35.

7. Shrestha M, Bachet J, Bavaria J, Carrel TP, De Paulis R, Di Bartolomeo R, et al. Current status and recommendations for use of the frozen elephant trunk technique: a position paper by the Vascular Domain of EACTS. Eur J Cardiothorac Surg. 2015:47:759-69.

8. Ma WG, Zhang W, Wang LF, Zheng J, Ziganshin BA, Charilaou P, et al. Type A aortic dissection with arch entry tear: Surgical experience in 104 patients over a 12-year period. J Thorac Cardiovasc Surg. 2016:151:1581-92.

9. Parikh N, Trimarchi S, Gleason TG, Kamman AV, di Eusanio M, Myrmel T, et al. Changes in operative strategy for patients enrolled in the International Registry of Acute Aortic Dissection interventional cohort program. J Thorac Cardiovasc Surg. 2017;153:S74-9.

10. Hanif H, Dubois L, Ouzounian M, Peterson MD, El-Hamamsy I, Dagenais $F$, et al. Aortic arch reconstructive surgery with conventional techniques vs frozen elephant trunk: a systematic review and meta-analysis. Can J Cardiol. 2018;34:262-73.

11. Czerny M, Schmidli J, Bertoglio L, Carrel T, Chiesa R, Clough RE, et al. Clinical cases referring to diagnosis and management of patients with thoracic aortic pathologies involving the aortic arch. Eur J Vasc Endovasc Surg. 2019;57:452-60.

12. Di Bartolomeo R, Murana G, Di Marco L, Alfonsi J, Gliozzi G, Amodio C, et al. Is the frozen elephant trunk frozen? Gen Thorac Cardiovasc Surg. 2019;67:111-7

13. Sun $X$, Guo H, Liu Y, Li Y. The aortic balloon occlusion technique in total arch replacement with frozen elephant trunk. Eur J Cardiothorac Surg. 2019:55:1219-21.

14. Yan TD, Tian DH, LeMaire SA, Hughes GC, Chen EP, Misfeld M, et al. Standardizing clinical end points in aortic arch surgery: a consensus statement 
from the International Aortic Arch Surgery Study Group. Circulation. 2014;129:1610-6.

15. Qi RD, Zhu JM, Liu YM, Chen L, Li CN, Xing XY, et al. The repair of a type la endoleak following thoracic endovascular aortic repair using a stented elephant trunk procedure. J Thorac Cardiovasc Surg. 2018;155:1391-6.

16. Tew S, Fontes ML, Greene NH, Kertai MD, Ofori-Amanfo G, Jaquiss RD, et al. Natural history of nonimmune-mediated thrombocytopenia and acute kidney injury in pediatric open-heart surgery. Paediatr Anaesth. 2017:27:305-13.

17. Koo CH, Eun Jung D, Park YS, Bae J, Cho YJ, Kim WH, et al. Neutrophil, Iymphocyte, and platelet counts and acute kidney injury after cardiovascular surgery. J Cardiothorac Vasc Anesth. 2018;32:212-22.

18. Chin JH, Jo JY, Lee EH, Kim WJ, Choi DK, Sim JY, et al. Prognostic impacts of increases in amino transaminases following coronary artery bypass grafting on mortality. J Cardiothorac Vasc Anesth. 2018;32:1236-42.

19. Adachi K, Toyama H, Kaiho Y, Adachi O, Hudeta H, Yamauchi M. The impact of liver disorders on perioperative management of reoperative cardiac surgery: a retrospective study in adult congenital heart disease patients. J Anesth. 2017;31:170-7.

20. van Boxtel AG, Bramer S, Soliman Hamad MA, van Straten AH. Perioperative serum aspartate aminotransferase level as a predictor of survivalafter coronary artery bypass grafting. Ann Thorac Surg. 2012;94:1492-8.

21. Liu Z, Pang X, Zhang X, Cao G, Fang C, Wu S. Incidence and risk factors of delirium in patients after type-A aortic dissection surgery. J Cardiothorac Vasc Anesth. 2017;31:1996-9.

22. Weerasinghe A, Athanasiou T, Philippidis P, Day J, Mandal K, Warren O, et al. Platelet-monocyte pro-coagulant interactions in on-pump coronary surgery. Eur J Cardiothorac Surg. 2006;29:312-8.

23. Xu K, Chan NC, Hirsh J, Ginsberg JS, Bhagirath V, Kruger P, et al. Quantifying immature platelets as markers of increased platelet production after coronary artery bypass grafting surgery. Eur J Haematol. 2018;101:362-7.

24. Silberman S, Abu-Yunis U, Tauber R, Shavit L, Grenader T, Fink D, et al. Neutrophil-lymphocyte ratio: prognostic impact in heart surgery. Early outcomes and late survival. Ann Thorac Surg. 2018;105:581-6.
25. Kalkan ME, Kalkan AK, Gündeş A, Yanartaş M, Oztürk S, Gurbuz AS, et al. Neutrophil to lymphocyte ratio: a novel marker for predicting hospital mortality of patients with acute type A aortic dissection. Perfusion. 2017:32:321-7.

26. Sbarouni E, Georgiadou P, Analitis A, Voudris V. High neutrophil to lymphocyte ratio in type A acute aortic dissection facilitates diagnosis and predicts worse outcome. Expert Rev Mol Diagn. 2015;15:965-70.

27. Oz K, Iyigun T, Karaman Z, Çelik Ö, Akbay E, Akınc O, et al. Prognostic value of neutrophil to lymphocyte ratio and risk factors for mortality in patients with stanford type A aortic dissection. Heart Surg Forum. 2017;20:E119-23.

28. Wang Y, Ji H. Comparison of two different red blood cell transfusion thresholds on short-term clinical outcomes of patients undergoing aortic surgery with deep hypothermic circulatory arrest. J Cardiothorac Vasc Anesth. 2016;30:1163-6.

29. Keenan JE, Wang H, Gulack BC, Ganapathi AM, Andersen ND, Englum $B R$, Krishnamurthy $Y$, et al. Does moderate hypothermia really carry less bleeding risk than deep hypothermia for circulatory arrest? A propensitymatched comparison in hemiarch replacement. J Thorac Cardiovasc Surg. 2016;152:1559-1569.e2.

30. Conzelmann LO, Weigang E, Mehlhorn U, Abugameh A, Hoffmann I, Blettner $\mathrm{M}$, et al. Mortality in patients with acute aortic dissection type $\mathrm{A}$ : analysis of pre- and intraoperative risk factors from the German Registry for Acute Aortic Dissection Type A (GERAADA). Eur J Cardiothorac Surg. 2016;49:e44-52.

\section{Publisher's Note}

Springer Nature remains neutral with regard to jurisdictional claims in published maps and institutional affiliations.
Ready to submit your research? Choose BMC and benefit from:

- fast, convenient online submission

- thorough peer review by experienced researchers in your field

- rapid publication on acceptance

- support for research data, including large and complex data types

- gold Open Access which fosters wider collaboration and increased citations

- maximum visibility for your research: over 100M website views per year

At BMC, research is always in progress.

Learn more biomedcentral.com/submissions 